\title{
Human Resource Development Indicators for the Iranian Judo Federation
}

\author{
${ }^{1}$ Mohammad Ali Noudehi, ${ }^{1}$ Morteza Doosti ${ }^{*}$ 'Seyed Mohammad Hossein Razavi, \\ ${ }^{1}$ Masomeh Kalateseifari \\ ${ }^{\mathbf{1}}$ Department of Sport Management, Faculty of Sport Sciences, University of Mazandaran, Babolsar, Iran.
}

\begin{abstract}
Objectives. The aim of this study was to identify and prioritize human resource development indicators for the Iranian Judo Federation. Methods. The present study was a combined (mixed) research. The research population consisted of officials from the Federation, the national team coaches and members, delegation officials, university professors, and other experts $(\mathrm{n}=96)$. The sampling was purposeful and based on availability. The data were collected by both - interviews and a researcher-designed questionnaire. Its content validity was confirmed by 10 professors who worked in the field of sports management. The reliability of the questionnaire was obtained using Cronbach's coefficient alpha ( $\alpha=0.79$ ). Results. According to the study, the four factors (in order of priority) for the development of human resources were as follows: motivation, training and promotion, performance evaluation, and absorption of the human resources. Conclusion. According to the results, motivation is the most important factor for the development of human resources and the Judo Federation authorities need to focus attention on motivational strategies to enhance performance and develop their country's human resources in this particular sport.
\end{abstract}

KEY WORDS: Motivation, Training And Promotion, Performance Evaluation, Human Resources Absorption, Development, Judo Federation.

\section{INTRODUCTION}

Human resource management is a system that recognizes the importance of people in an organization. The proper management of people maximizes their performance in service of the organization's strategic objectives, thus enhancing customer service, entrepreneurship, quality, etc. (1). In general, it can be said that human resource management includes: recruitment and employment, training and development, recruitment and appointment, and encourages the human resources to achieve organizational goals. These are the four basic processes of human resource management based on which the models, systems and methods should be designed. Human resource development is a set of activities planned to obtain a set of desirable individual and organizational results. Over the past two decades, some attempts have been carried out using a human resource development approach which included its definition, processes, concepts, and steps (2).

Given that nowadays, human resources are considered as the main asset of the organization,

*. Corresponding Author:

Morteza Doosti

E-mail: m_dostipasha@yahoo.com 
their duties and activities in addition to directly affecting the organization's performance, can also indirectly affect the organizational capital $(3,4)$.

According to Fathi, Sheibani, and Arefnejhad (2005), developing human resources has to be an organized, planned, and nationwide effort guided by senior-level managers. It has to be implemented in a regular and continuous manner with the aim of bringing about changes in beliefs, attitudes, structure, and organization (5).

Russell et al. (2016) reported that if the organization's authorities provide suitable opportunities for the staff to gain professional and occupational experience, the staff can use this opportunity to increase their knowledge, skills, and abilities and the result can be useful and effective for both the employee and the organization (6).

As a result of a factor analysis influencing the choice of solutions for human resource development, Kazakovs (2014) identified 12 different factors that can lead to the development of human resources in an organization. He reported that as a result, the human resource development could improve the performance of an organization (7).

In order to improve organizational performance, Agwu and Ogiriki (2014) recommended the review of teaching methods and current development, regular assessment of the needs of employees, holding regular training courses for the staff, improving the service conditions, and supportive and encouraging services for the staff (8).

In a study of 600 organizations in Greece, Katou and Budhwar (2007) concluded that the development of human resources through the development of skills, attitudes, and behavior has a positive impact on organizational performance (9).

Goharipor, Ghafoori, and Nadri (2013) reported that if the experts gain better scores in terms of ability, they will have a stronger motivation to perform the tasks (10).

In analyzing the strategies for human resource development in gymnastics, Badriazarin, Talebiannia, and Salmani (2013) concluded that factors such as absorption, training, promotion and fosterage, protection, and preservation of human resources are effective in the development of human resources in gymnastics (11).

Mirsepasi et al. (2014) designed a model of excellence for human resources in the Iranian state organizations and identified some factors such as (a) planning, recruitment and supply; (b) training and rehabilitation; (c) motivation and effective use; (d) maintenance (12).

Tabihi (2004) in his study examines the key factors in the development of human resources in the health sector and in particular hospitals and emphasized that planning of the human resources and training were key commands (13).

Golabi (2008) believes that human resource development is important to create scientific knowledge and improve employee knowledge, development and enhancement of employee capabilities and updating information (14).

The Iranian Judo Federation was established in 1975; but in spite of its history and experience, in the past years they have had certain challenges preventing them from meeting performance expectations at an international level. In recent years the qualitative development of human resources in judo has not been satisfactory; and in spite of being an Olympic sport and the country having a long history and considerable talent, there has been an inability to develop judo as a championship sport. Sadly, it has also failed to gain popularity amongst the Iranian population (15).

Furthermore, the national judo team's repeated defeats in the World Championships and the Olympics has caused a decline in public willingness to participate in this sport, and as a result the number of organized athletes active in judo has also decreased. Therefore, the country's sport authorities and the Judo Federation need to concentrate attention on planning and developing of human resources (16).

The present study is important and necessary because firstly, in recent years, judo as a sport in Iran has faced many issues in quantitative and qualitative development, and secondly, no specific scientific research has been done with regard to human resource development of judo in the country. Hence, the findings of the present research can provide some strategies for optimal development of human resources in Iranian judo. The results of this study can assist the authorities, the relevant stakeholders of the 
Federation, and provinces to adopt effective steps for the advancement and promotion of judo as a sport in Iran.

\section{MATERIALS AND METHODS}

Participants. The present study is an applied research using a combined (mixed) method. The sampling was non-randomized, purposeful and as available. In the qualitative phase, a modified classical Delphi method was used to develop indicators. In this phase, the statistical population consisted of the senior authorities, the members of the committees in the Federation, the national team coaches and some of the university professors involved in sports management. At the first stage of Delphi, 30 individuals took part, at the second stage and third stage - 20 and 15 individuals took part, respectively.

Data Collection. In this section, the data were collected by an interview method. At the quantitative stage, the research method was descriptive, using indices edited in Delphi.

Tools. A researcher-made questionnaire was distributed to the sports delegation authorities as well as the country's judo experts $(n=96)$. Eventually, 85 questionnaires were returned decreasing the sample size to 85 individuals. Instruments used at this stage included a researcher-made questionnaire which had four different dimensions: (a) creating motivation in human resources (Questions 1-7), (b) train and upgrade human resources (Question 7-18), (c) absorption of worthwhile human resources (Questions 1824), and (d) evaluating the performance of human resources (Questions 25-29); with a five-level Likert item scale content. The face validity of the questionnaire was confirmed by 10 professors specialized in sports management. The reliability of the questionnaire was obtained using Cronbach's coefficient alpha $(\alpha=0.79)$ which showed that the questionnaire had appropriate reliability.

Statistical Analysis. To analyze the data, descriptive statistics (frequencies, drawing tables) and analytical (exploratory factor analysis) was done using the SPSS20 software. In addition, to determine the construct validity, the confirmatory factor analysis was undertaken using the LISREL software, a value of 8.5 was calculated.

\section{RESULTS}

The sample distribution is shown in table 1 .

Table 1. Distribution of the Subjects

\begin{tabular}{lc}
\hline \multicolumn{1}{c}{ Respondents } & Frequency \\
\hline Federation authorities & $9(10.59 \%)$ \\
\hline Authorities of province delegations & $53(63.35 \%)$ \\
\hline National teams' coaches & $3(3.53 \%)$ \\
\hline National teams' athletes & $11(12.94 \%)$ \\
\hline experts & $9(10.59 \%)$ \\
\hline total & $85(100 \%)$ \\
\hline
\end{tabular}

Various indicators identified for the development of judo human resources is shown in table 2. Table 3 shows that the "Motivating the Human Resources" indicator has the highest average among different indices.

According to the results presented in Table 4 the factor analysis can be used.

For determining the priority of judo human development indexes, the exploratory factor analysis was used (Table 5). The results of Table 5 show that the factor "motivation in human resources" takes 69.824 percent of the variance, and because only the value of the motivation index is a bit higher than the standard one (2.793), it can be said that the four human resource development factors have a common coefficient in one factor.

According to the findings presented in Table 6, the "Motivating the Human Resources" indicator has the highest factor load and has the first priority among different indices. The findings for construct validity and verification of the questionnaire items are shown in Table 7. The fit indicators showed that the factors considered have good construct validity.

\section{DISCUSSION}

Based on the results of this study, the four indicators identified for the development of human resources in the Judo Federation are as follows: the first priority was related to "motivating the human resources" with a factor 
loading of 0.903 , the second priority was associated with the "training and promotion of human resources" with a factor loading of 0.873 , and the third priority was connected to the "employment of qualified human resources" with a factor loading of 0.745 .

Table 2. Scores of Human Resource Development judo items

\begin{tabular}{cccc}
\hline Index & Items & Mean & SD \\
\hline & Celebrating successful coaches & 4.58 & .51 \\
Motivating human resources & Celebrating the successful athletes & 4.52 & .50 \\
& Celebrating the successful referees & 3.82 & .77 \\
& Celebrating staff & 4.42 & .62 \\
& Sending out the top trainers to abroad & 4.50 & .54 \\
& Securing the national athletes' future & 4.42 & .58 \\
& Securing the national coaches' future & 4.18 & .77 \\
\hline & Increasing knowledge class for coaches & 3.25 & .86 \\
& Increasing knowledge class for referees & 3.75 & .96 \\
& Classes for promoting coaching & 3.52 & 1.04 \\
& Classes for promoting arbitration & 3.77 & 1.03 \\
& Increasing knowledge class for officials and staff & 3.81 & .91 \\
& The internal international games & 4.36 & .72 \\
& Joint camps with famous countries & 3.91 & .78 \\
& The country's Championship & 4.00 & .70 \\
& Holding Judo League & 4.20 & .72 \\
& Sending athletes to the prestigious tournament & 4.04 & .68 \\
\hline \multirow{2}{*}{ Attracting qualified human and promotion of human resources } & Recruitment of appropriate personnel & 3.74 & .75 \\
& Recruitment volunteers & 4.08 & .83 \\
& Attracting sponsors, donors, and investors & 3.84 & .74 \\
& Attracting qualified coaches & 3.38 & 1.00 \\
& Attract qualified referees & 4.07 & .76 \\
& Attracting qualified athletes & 3.47 & .92 \\
& Attracting new athletes & 3.32 & .66 \\
\hline & Evaluating the performance of coaches & 4.14 & .70 \\
& Evaluating the performance of referees & 3.72 & .95 \\
& Evaluating the performance of athletes & 3.88 & .86 \\
& Evaluating the performance of authorities & 3.95 & .70 \\
& Evaluating the performance of staff & 3.96 & 74 \\
\hline
\end{tabular}

Table 3. Judo human resource development index advantages

\begin{tabular}{ccc}
\hline Indicators & Mean & St.d \\
\hline Motivating the human resources & 4.35 & 0.22 \\
\hline Training and promotion of the human resources & 3.85 & 0.30 \\
\hline Attracting qualified human resources & 3.84 & 0.31 \\
\hline Evaluating the performance of the human resources & 3.93 & 0.38 \\
\hline
\end{tabular}

Table 4. The KMO and Bartlett tests to check the adequacy of samples for analysis

\begin{tabular}{ccccc}
\hline \multicolumn{3}{c}{ Bartlett's Test of Sphericity } & \multirow{2}{*}{ KMO Measure of Sampling Adequacy } \\
\cline { 1 - 2 } Approx. Chi-Square & df & Sig. & & 0.68 \\
\hline 201.253 & 6 & 0.001 & \\
\hline
\end{tabular}

As indicated by these findings, the first priority for the development of human resources in the Judo Federation was to motivate the people. Taking into account the motivational factors for employees, their needs and considering the individual differences is a factor 
of utmost importance in achieving labor productivity. A key necessary condition to achieve the goals of any business is to motivate the individuals who work for that business (16). Agwu and Ogiriki (2014) reported that human resource development can lead to increased motivation and employee commitment (8). Badriazarin, Talebiannia, and Salmani (2013) concluded that the variable of "maintenance" which is created through motivating individuals had the greatest impact on human resource development at the Azerbaijan Gymnastics Federation in east Azerbaijan province, Iran (11). Alidoust Ghahfarokhi et al. (2014) presented that motivational support of human resources was among the main strategies required for the development of judo; in this regard, he recommended warranting athletes with housing and educational facilities, financial support to coaches and athletes, providing career opportunities for the national team's athletes, etc. (17). Krausert (2017) and Ghosh and Gurunathan (2015) concluded that there is a significant relationship between psychological empowerment's factor and the organizational performance $(18,19)$. The findings of the present study regarding the importance of "motivation in human resources" are consistent with the results of some other studies $(8,11,17$ 20).

Table 5. The total explained variance in human resource development index of judo

\begin{tabular}{cccc|ccc}
\hline & \multicolumn{3}{c|}{ Initial Eigenvalues } & \multicolumn{3}{c}{$\begin{array}{c}\text { Extraction Sums of Squared } \\
\text { Loadings }\end{array}$} \\
\hline Component & Total & $\begin{array}{c}\% \text { of } \\
\text { Variance }\end{array}$ & $\begin{array}{c}\text { Cumulative } \\
\%\end{array}$ & Total & $\begin{array}{c}\% \text { of } \\
\text { Variance }\end{array}$ & $\begin{array}{c}\text { Cumulative } \\
\%\end{array}$ \\
\hline Motivating the human resources & 2.793 & 69.824 & 69.825 & 2.793 & 69.824 & 69.825 \\
\hline $\begin{array}{c}\text { Training and promotion of the } \\
\text { human resources }\end{array}$ & 0.691 & 17.275 & 87.099 & & & \\
\hline $\begin{array}{c}\text { Evaluating the performance of the } \\
\text { human resources }\end{array}$ & 0.306 & 7.650 & 94.749 & & \\
\hline $\begin{array}{c}\text { Attracting qualified human } \\
\text { resources }\end{array}$ & 0.210 & 5.245 & 100 & & \\
\hline
\end{tabular}

Table 6. Matrix factors and factor loadings human resources development indicators Judo

\begin{tabular}{cc}
\hline Indicators & Factor Loading \\
\hline Motivating the human resources & 0.903 \\
\hline Training and promotion of the human resources & 0.837 \\
\hline Evaluating the performance of the human resources & 0.814 \\
\hline Attracting qualified human resources & 0.745 \\
\hline
\end{tabular}

Table 7. Studying the indices of goodness of fit

\begin{tabular}{cccccc}
\hline RMSEA & GFI & NFI & CFI & AGFI & X $^{2} / \mathrm{df}$ \\
\hline 0.071 & 0.93 & 0.95 & 0.96 & 0.90 & 1.91 \\
\hline
\end{tabular}

The second priority identified in this study was related to the "training and upgrading of the human resources". In this regard, holding coaching and refereeing classes, enhancing the knowledge of coaches and referees as well as holding some tournaments and sports camps for the athletes should be considered. Russell et al. (2016) concluded that increasing the knowledge and skills of employees through training programs can lead to an improvement of employees' performance and consequently improve the performance of the organization (6). Katou and Budhwar (2007) reported that human resource development through increasing of the level of skills can lead to an improved organizational performance (9). Noudehi (2012) reported that in 
order to improve the level of judo in Iran, integrated training classes should be held for coaches across the country (16). Alidoust Ghahfarokhi et al. (2014) concluded that one the most important strategies for the development of Iran's judo level is to utilize an integrated training system for the coaches across the country as well as promote their scientific and technical knowledge through local courses as well as foreign courses for which they could travel abroad (17). The results of the study conducted by
Batarlienè et al. (2017) and Kazakovs, Verdina, and Arhipova (2015) indicated that enhancing the scientific and technical knowledge of gymnastics coaches as a strategy has contributed greatly to helping gymnastics achieve a championship level $(21,22)$. Our findings were consistent with the results of some other studies that suggested the importance of considering the role of human resource training and promotion in the improvement of the organizational performance $(6,9,11,16,17,21,22)$.



Figure 1. The results of confirmatory factor analysis of human resource development indicators for Judo

Among the identified indicators, the third priority for the development of human resources in judo was associated with the "performance evaluation of human resources". Aryanto, Fontana, and Afiff (2015) and Liao and Huang (2016) reported that it is necessary to develop an evaluation system as a powerful tool for the assessment of the Federation's performance, determination of the achievement level for predetermined goals as well as for the selfassessment of the Federation (23, 24). Alidoust Ghahfarokhi et al. (2014) put emphasis on some other strategies for the improvement of Iran's judo including the creation and deployment of a monitoring and control system in the Federation and provincial boards as well as monitoring the activities of coaches (17). Agwu and Ogiriki (2014) and Becker and Smidt (2016) reported that regular evaluation of the employees' occupational needs as well as reviewing training methods can empower staff, thus leading to an increased level of productivity $(8,25)$. O'Boyle (2015) has also presented a specific pattern for the assessment of coaches and young athletes that includes the assessment of contests, competitions, and team exercises (26). The Hartwick College has also developed some questionnaires in order to evaluate the performance of coaches by the Head coaches, the department of physical education, the samelevel coaches, students and sports captains (27). The findings of the present study regarding the importance of performance evaluation of human resources in the development of human resources are consistent with the findings of some other studies $(7,20,21,27-29)$.

Attracting and "employment of qualified human resources" was the fourth identified 
priority for the development of human resources in the judo sport. Agwu and Ogiriki (2014) reported that considering the knowledge and skills of individuals during recruitment can lead to improved organizational performance (8). Hashemi and PoorAminzad (2011) and Filo, Cuskelly, and Wicker (2015) suggested that for the development of human resources, managers should try to hire professional and competent staff, then motivate them and provide some opportunities for knowledge and skill improvement. For the development of judo (1, 30), Ghahfarokhi et al. (2014) suggested that it is necessary that there be knowledgeable experts appointed, such as an experienced and skilled manager as the Federation's president, employment of a prominent foreign coach, a psychologist, a fitness coach, and a nutritionist in the national teams (17). Noudehi (2012) reported that the use of efficient judo coaches (national and foreign) and utilizing them at different age categories can contribute to the development of judo (16). Mirsepasi et al. (2014) pointed out that the planning and employment of a skilled and specialist workforce is an important component of human resource development in public organizations (12). The findings of the present study on the importance of "employment of qualified human resources" and its impact on the organizational performance are consistent with the results of other studies $(2$, $8,12,16,17,30,31)$.

\section{CONCLUSION}

In general, it can be concluded that the organizational development of human resources can lead to the improvement of its performance and, therefore, this issue should be considered by the authorities. Accordingly, keeping in mind the current situation of judo in Iran, the Federation's authorities should focus on different aspects of this sport, mainly motivating individuals (including the athletes, coaches, referees, and other employees), training them, and improving their level of knowledge and skills, assessment of their performance, and employing a qualified workforce.

\section{APPLICABLE REMARKS}

- In order to motivate deserving coaches and athletes, they should be granted welfare facilities and rewards.

- To enhance the skill level of athletes, preparatory competitions and international joint camps should be held.

- To enhance the knowledge and the skill level of the country's judo athletes and coaches, some prominent foreign coaches should be invited to Iran.

- To increase the level of knowledge and skills of employees in the Judo Federation and provinces' councils, holding certain skill-enhancement training programs is recommended.

- To improve the performance of individuals, an annual performance evaluation should be done. At the time of recruitment, aptitude and skill tests relevant to the considered duties should be conducted.

\section{REFERENCES}

1. Hashemi SA, PoorAminzad S. The challenges facing human resource development and the way to fix it. Work and Society. 2011:4-21 [Article in Farsi].

2. Li A, McCauley KD, Shaffer JA. The influence of leadership behavior on employee work-family outcomes: A review and research agenda. Human Resource Management Review. 2017;27(3):458-72.

3. Amirkhani T, Sepahvand R, Aref Nejad M. The Practices of Human Resource Management and Organizational Performance: Considering the Role of Social Capital and Psychological Capital. Iranian journal of management sciences. 2014;9(34):105-24 [Article in Farsi].

4. Delgoashaee B, Tabibi S, Pahlevan P. Designing a human resource development model for the health sector of Iran. Research in Medicine. 2007;31(4):317-25 [Article in Farsi].

5. Fathi N, Sheibani R, Arefnejhad M. Hidden pearls: Saipa future manager's development. Tehran, Iran: CulturalSport Institute of Saipa (Nourbakhsh); 2005. 160 [Book in Farsi] p. 
6. Russell ZA, Ferris GR, Thompson KW, Sikora DM. Overqualified human resources, career development experiences, and work outcomes: Leveraging an underutilized resource with political skill. Human Resource Management Review. 2016;26(2):125-35.

7. Kazakovs M. Analysis of Factors Influencing the Choice of Solutions for Human Resource Development. Procedia - Social and Behavioral Sciences. 2014;156(Supplement C):111-5.

8. Agwu MO, Ogiriki T. Human Resource Development and Organizational Performance in the Nigeria Liquefied Natural Gas Company Limited, Bonny. Journal of Management and Sustainability. 2014;4(4):134-46.

9. Katou AA, Budhwar PS. The effect of human resource management policies on organizational performance in Greek manufacturing firms. Thunderbird International Business Review. 2007;49(1):1-35.

10. Goharipor MS, Ghafoori F, Nadri A. The Relationship Empowerment Factors and Motivation of Human Resources Work Tasks Islamic Republic of Iran Physical Education Organization (Ministry of Sport \&amp; Youth). Sport Management Studies. 2013;5(19):93-108 [Article in Farsi].

11. Badriazarin Y, Talebiannia H, Salmani A. Strategies in the Human Resources Development of Gymnastic Sport. Sport Management Studies. 2013;5(19):81-92.

12. Mirsepasi N, Memarzadeh G, Najafbeigi R, Alizadeh M. Model for Excellence in The Public Sector (Case Study Of The Public Organization In Iran). Journal of Executive Management. 2014;5(10):157-80 [Article in Farsi].

13. Tabihi SJ. Human Resources Development In The Hospital. Teb Va Tazkieh. 2004;12(3):9-23 [Article in Farsi].

14. Golabi S. Management organization and Human resource development. Tehran, Iran: Ferdos Publication; 2008. 240 [Book in Farsi] p.

15. Farzboud B. The Comparison of Physical fitness and anthropometric factors in elite and amatour judocas. Tehran, Iran. Shahid Rajaee University, . Tehran, Iran: Shahid Rajaee University of Teacher Training; 2014 [Thesis in Farsi].

16. Noudehi MA. Investigate the causes of the failure of members of Iran's national judo team in the World Championships and Olympics. 1st National Conference of New Achievements in Sports Science; Gorgan, Iran2012 [Article in Farsi].

17. Alidoust Ghahfarokhi E, Sajjadi SN, Mahmoudi A, Sa'atchian V. The Evaluation of Development Priorities and Strategies of Judo Championship in Iran. Journal of Sport Management. 2014;6(2):231-46 [Article in Farsi].

18. Ghosh D, Gurunathan L. Do commitment based human resource practices influence job embeddedness and intention to quit? IIMB Management Review. 2015;27(4):240-51.

19. Krausert A. HR differentiation between professional and managerial employees: Broadening and integrating theoretical perspectives. Human Resource Management Review. 2017;27(3):442-57.

20. Iversen EB, Cuskelly G. Effects of different policy approaches on sport facility utilisation strategies. Sport Management Review. 2015;18(4):529-41.

21. Batarlienė N, Čižiūnienė K, Vaičiūtè K, Šapalaitè I, Jarašūnienė A. The Impact of Human Resource Management on the Competitiveness of Transport Companies. Procedia Engineering. 2017;187(Supplement C):110-6.

22. Kazakovs M, Verdina A, Arhipova I. Automation of Human Resources Development Planning. Procedia Computer Science. 2015;77(Supplement C):234-9.

23. Aryanto R, Fontana A, Afiff AZ. Strategic Human Resource Management, Innovation Capability and Performance: An Empirical Study in Indonesia Software Industry. Procedia - Social and Behavioral Sciences. 2015;211(Supplement C):874-9.

24. Liao K-H, Huang IS. Impact of Vision, Strategy, and Human Resource on Nonprofit Organization Service Performance. Procedia - Social and Behavioral Sciences. 2016;224(Supplement C):20-7.

25. Becker K, Smidt M. A risk perspective on human resource management: A review and directions for future research. Human Resource Management Review. 2016;26(2):149-65.

26. O'Boyle I. Developing a performance management framework for a national sport organisation. Sport Management Review. 2015;18(2):308-16.

27. Barber H, Eckrich J. Methods and Criteria Employed in the Evaluation of Intercollegiate Coaches. Journal of Sport Management. 1998;12(4):301-22.

28. Nishigaki F, Ezoe S, Kitajima H, Hata K. Human resource development contributes to the creation of outstanding regenerative medicine products. Regenerative Therapy. 2017;7(Supplement C):17-23.

29. Wilpert B. Organizational Behavior, Psychology of A2 - Smelser, Neil J. In: Baltes PB, editor. International Encyclopedia of the Social \& Behavioral Sciences. Oxford: Pergamon; 2001. p. 10917-21.

30. Filo K, Cuskelly G, Wicker P. Resource utilisation and power relations of community sport clubs in the aftermath of natural disasters. Sport Management Review. 2015;18(4):555-69.

31. Sounthornwiboon P, Srichaisawat P, Sriprasertpap K. The Development of a MIS Model for Elite Sports Development Department of SAT Thailand. Procedia - Social and Behavioral Sciences. 2015;197(Supplement C):1926-30. 